\title{
Molecular Diversity of Cipadessa baccifera (Roth) Miq Based on Inter Simple Sequence Repeats
}

\author{
E. Jebarubi, S. Christopher Patrick Kiladi, T. Leon Stephan Raj ${ }^{*}$ \\ Postgraduate and Research Department of Botany, St. Xavier's College (Autonomous), Palayamkottai, Tirunelveli, Tamil Nadu, India
}

Email address:

leostephanraj@gmail.com (T. L. S. Raj)

${ }^{*}$ Corresponding author

\section{To cite this article:}

E. Jebarubi, S. Christopher Patrick Kiladi, T. Leon Stephan Raj. Molecular Diversity of Cipadessa baccifera (Roth) Miq Based on Inter Simple Sequence Repeats. International Journal of Biomedical Materials Research. Vol. 5, No. 1, 2017, pp. 1-4. doi. 10.11648/j.ijbmr.20170501.11

Received: October 31, 2016; Accepted: November 15, 2016; Published: January 13, 2017

\begin{abstract}
Medicinal plants are nature's gifts and used in different traditional medicinal systems of India. Most of the medicinal plants are obtained from forest without proper management and knowledge of collection. For the authentication of medicinal plants from the substituted materials, a genetic diversity study is necessary. In the present investigation molecular diversity of Cipadessa baccifera was carried out using dominant ISSR (inter simple sequence repeats) markers in four different accessions of Western Ghats of South India. Five primers were selected from a total of ten primers based on the reproducibility of the bands. The number of polymorphic loci was 13 and the percentage of polymorphic loci was 56.52. The genetic distance among the populations ranged from 0.0910 to 0.3629 and the genetic identity ranged from 0.6087 to 0.9130 . The overall observed and effective number of alleles was about 1.5652 and 1.3913. Nei's overall genetic diversity and Shannon information index were 0.2283 and 0.3349 . The dendrogram was constructed based on the UPGMA method and the clusters formed depending upon the genetic characters.
\end{abstract}

Keywords: Molecular Diversity, Inter Simple Sequence Repeats (ISSR), Cipadessa baccifera, Medicinal Plants

\section{Introduction}

Cipadessa baccifera is a shrub mainly grows in the tropical areas of Asia [1]. It is one of well-known traditional medicines in India for the treatment of rheumatoid arthritis, dysentery and pruritus [2], the paste of root, leaf and bark of this plant are applied for topically to cure psoriasis [3]. Its decoction has been utilized to treat dysentery, skin itches and malaria fevers by tribal community $[4,5]$. The methanol and chloroform extracts of leaves were evaluated for antimicrobial, antioxidant, hemolytic and thrombolytic activities [6]. In spite of the economic and medicinal values of $C$. baccifera no serious attention should be paid to diversity, characterization and taxonomical identification at the molecular level. This is a prerequisite to the exploitation of the vast genetic variability available for the improvement of the quality and quantity of their drug contents. The plant mainly collected from the wild environment. Therefore the identification and collection process had a serious problem. It leads to the adulteration in drug preparation. To overcome this problem, the molecular level authentication of medicinal plants is necessary with the help of molecular markers.

Molecular markers for assessment of genetic variation in plant have shown many advantages. They are neutral, not related to age and tissue type, and not influenced by the environmental conditions, have feasibility and lower costs, and are more informative than morphological markers. Thus, molecular markers can be considered to be more effective approach compared to morphological markers to identify plant genotypes in a germplasm or fruit trees collection [7]. DNA markers play an essential role in the study of genetic variability and diversity, in the construction of linkage maps and in the diagnosis of individuals or lines carrying certain linked genes [8]. DNA based molecular markers have acted as flexible tool and have found its application in various fields like taxonomy, genetic engineering, physiology etc. [9, 
10]. Inter simple sequence repeats (ISSR) have been proven to be a simple and reliable marker system for many organisms, especially plants, with highly reproducible results and abundant polymorphisms. ISSR analysis has been successfully applied in gene tagging [11-14], variety of fingerprinting or genetic diversity analysis [15-17]. In the present investigation molecular diversity of $C$. baccifera of four different accessions of Western Ghats of South India was carried out using dominant ISSR markers.

\section{Materials and Methods}

The experimental material selected for the present study was $C$. baccifera and belongs to the family Meliaceae. The plant identification was taxonomically confirmed with specimens of St. Xavier's College Herbarium $(\mathrm{XCH})$. The young leaf samples of $C$. baccifera were collected from four accessions (Manimutharu, Papanasam, Courtallum and Puliankudi) of Western Ghats for ISSR studies.

\subsection{DNA Isolation}

Genomic DNA from the young leaves was isolated by the CTAB method [18]. Quantity was also checked spectrophotometrically from the absorbance data of the sample DNA at $260 / 280 \mathrm{~nm}$. The purity of the DNA sample was calculated from OD260/OD280 and its ratio ranged from 1.5 to 1.9 [19].

\subsection{ISSR-PCR Analysis}

PCR amplification reactions were carried out in a $20 \mu \mathrm{l}$ reaction volume which contained $2 \mathrm{X}$ Premix Taq HS (TaKaRa), $1 \mu \mathrm{L}$ of DNA and $1 \mu \mathrm{L}$ of ISSR primers. There are five primers UBC-808 (AGAGAGAGAGAGAGAGC), UBC-810 (GAGAGAGAGAGAGAGAT), UBC-811 (GAGAGAGAGAGAGAGAC), UBC-825 (ACACACACACACACACT) and UBC-834 (AGAGAGAGAGAGAGAGT) selected from ten primers based on the reproducibility of the bands. The PCR amplification was carried out in a PCR thermal cycler (GeneAmp PCR System 9700, Applied Biosystems). The components were mixed gently and amplification was carried out for 40 cycles. After initial heat denaturation of the DNA at $98^{\circ} \mathrm{C}$ for $30 \mathrm{sec}$ the thermal cycling was performed with the following temperature regimes $98^{\circ} \mathrm{C}$ for $5 \mathrm{sec}, 37^{\circ} \mathrm{C}$ for $120 \mathrm{sec}$ and $72^{\circ} \mathrm{C}$ for $60 \mathrm{sec}$. The final extension step was performed at $72^{\circ} \mathrm{C}$ for $300 \mathrm{sec}$ followed by cooling at $4^{\circ} \mathrm{C}$ for completion of the programme.

\subsection{Agarose Gel Electrophoresis of PCR Products}

The PCR products were checked in $1.2 \%$ agarose gels prepared in $0.5 \mathrm{X}$ TBE buffer containing $0.5 \mu \mathrm{g} / \mathrm{ml}$ ethidium bromide. $1 \mu \mathrm{L}$ of $6 \mathrm{X}$ loading dye was mixed with $5 \mu \mathrm{L}$ of PCR products and was loaded and electrophoresis was performed at $75 \mathrm{~V}$ power supply with $0.5 \mathrm{X}$ TBE as electrophoresis buffer for about 1-2 $\mathrm{h}$, until the bromophenol blue front had migrated to almost the bottom of the gel. The molecular standard used was 2-log DNA ladder (NEB). The gels were visualized in a UV transilluminator (Genei) and the image was captured under UV light using Gel documentation system (Bio-Rad).

\subsection{Data Analysis}

The banding patterns were scored based on the presence or absence of clear, visible and reproducible bands [20]. The similarity index of individuals was calculated following the method by Nei and Li [21]. The pair wise genetic distance among the populations was calculated using Pop gene package version 1.31 .

\section{Results and Discussion}

In the present study ISSR markers based on DNA fingerprinting were used to assess the genetic diversity among four different populations of Western Ghats of $C$. baccifera. Five primers were screened based on the reproducibility of the bands. The amplified DNA products were appeared in different molecular weight range. The same type of bands occurred at different frequencies in all populations. The total numbers of bands produced in each population are displayed in Figure 1 and total number bands produced by each primer are displayed in Figure 2. The number of polymorphic loci was 13 and the percentage of polymorphic loci was 56.52 . The genetic distance among the populations ranged from 0.0910 to 0.3629 and the genetic identity ranged from 0.6087 to 0.9130 (Table 1). The genetic variation statistics were displayed in Table 2 . The overall observed and effective number of alleles was about 1.5652 and 1.3913. Nei's [22] overall genetic diversity and Shannon information index were 0.2283 and 0.3349 . The similarity matrix obtained in the present study was used to construct a dendrogram with the UPGMA method and resulted in their distant clustering in the dendrogram (Figure 3).

In the dendrogram, the four collected accessions were divided into three major clusters based on the genetic distance. The first cluster showing more similarity between two accessions Manimutharu and Courtallum. The second cluster consists of Papanasam accession which showing more similarity with first cluster and dissimilarity with second cluster. The Puliyankudi accessions separately form the third cluster, which shows more genetic variation to other three accessions.

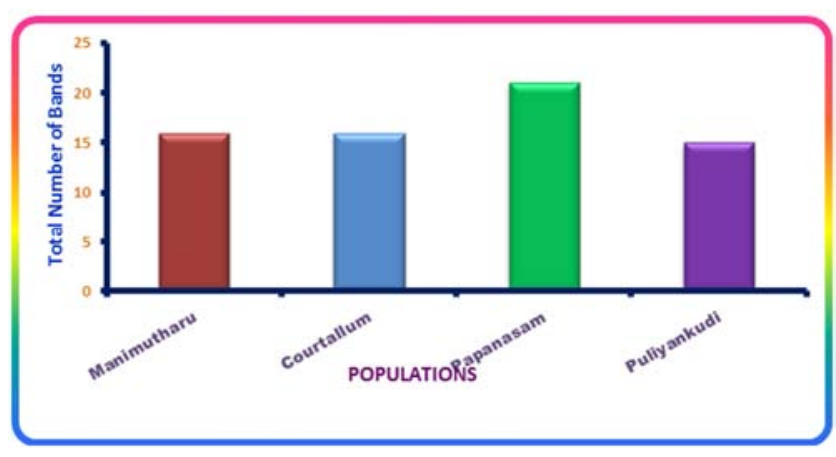

Figure 1. Total number of ISSR bands produced in each population. 


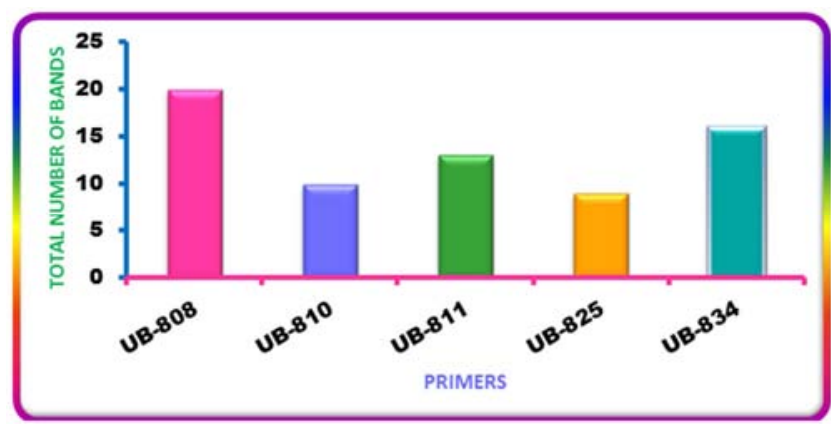

Figure 2. Total number of bands produced by different primers.

Table 1. Nei's original measures of genetic identity and genetic distance.

\begin{tabular}{lllll}
\hline Pop ID & $\mathbf{1}$ & $\mathbf{2}$ & $\mathbf{3}$ & $\mathbf{4}$ \\
\hline 1 & $* * * *$ & 0.9130 & 0.6957 & 0.6087 \\
2 & 0.0910 & $* * * *$ & 0.6957 & 0.6087 \\
3 & 0.3629 & 0.3629 & $* * * *$ & 0.6522 \\
4 & 0.4964 & 0.4964 & 0.4274 & $* * * *$ \\
\hline
\end{tabular}

Nei's genetic identity (above diagonal) and genetic distance (below diagonal).

Table 2. Summary of genetic variation statistics for all Loci.

\begin{tabular}{lll}
\hline Statistic parameters & Mean value & Standard deviation \\
\hline Observed number of alleles (a) & 1.5652 & 0.5069 \\
Effective number of alleles (ne) & 1.3913 & 0.3741 \\
Nei's(1973) gene diversity (h) & 0.2283 & 0.2087 \\
Shannon's information index (I) & 0.3349 & 0.3033 \\
\hline
\end{tabular}

4.549

pop1Manimuthare

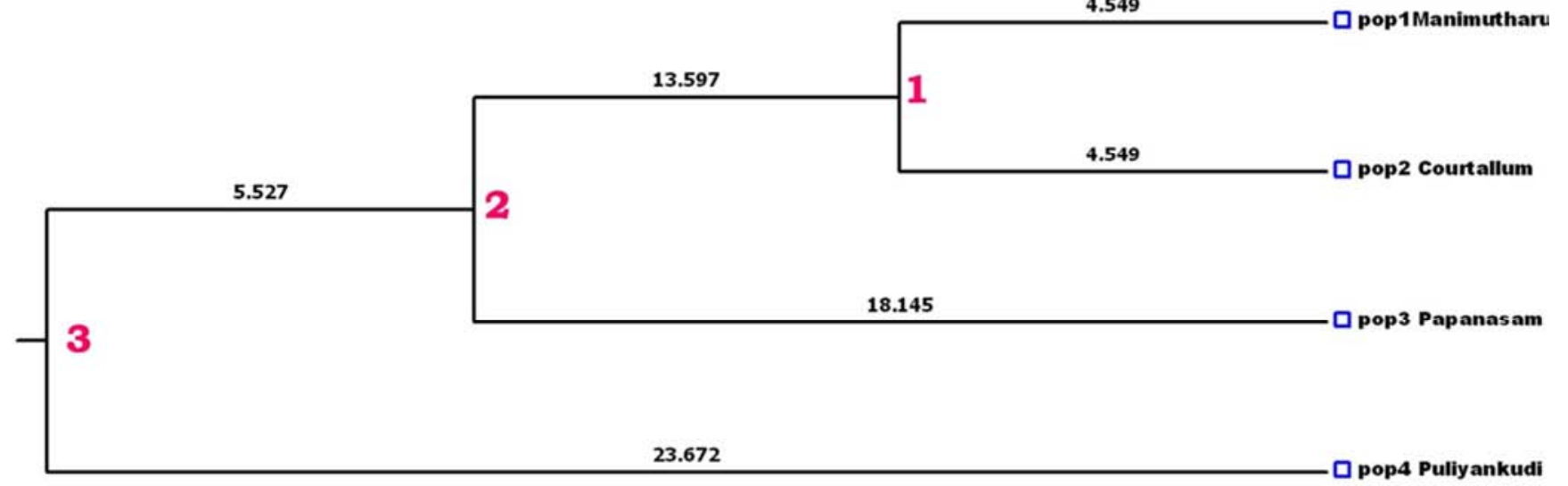

Figure 3. Dendrogram based on Nei's (1978) [23] Genetic distance Method = UPGMA Modified from NEIGHBOR procedure of PHYLIP Version 3.5.

The use of molecular markers has become a common practice in study of population structure, genetic diversity for pre-breeding and breeding germplasm and in distinguishing one individual genotype to preserve the property of breeding rights [24]. In addition, ISSR markers are useful in areas of genetic diversity, phylogenetic studies, gene tagging, genome mapping and evolutionary biology in a wide range of plant species [25, 26]. ISSR markers have been used to authenticate various medicinal important plants. Because various medicinal plants have been adulterated with some inferior and cheapest material from plant source. Correct botanical identification is possible by the use of ISSR markers, so that better quality herbal drugs can be used. This can be used for detection of adulteration thereby helping quality control. There are many examples of use of ISSR markers in pharmacognosy. Authentication of most popular mushroom Flammulina velutipes was done using strain specific sequence characterized amplified region (SCAR) developed from markers. Eight primers selected from 20 amplified 104 clear and stable bands, of which 81 were polymorphic [27].

\section{Conclusion}

Molecular diversity studies will help to know the genetic characters of the plants. ISSR constitute a powerful dominant DNA molecular marker system used for diversity analysis, which is indispensable for making estimates of genetic base and demarcation of populations for undertaking conservation and improvement program of forest tree species.

\section{References}

[1] Chetty, K. M, Sivaji, K. and Rao, K. T. Flowering Plants of Chittor District Andhra Pradesh, India. 1st ed. Tirupati. Students Offset Printers, 2008, Pp. 64.

[2] Roy, A. and Shailendra, S. (2006). Limonoids. Overview of significant bioactive triterpenes distributed in plants kingdom. Biological and Pharmaceutical Bulletin,29(2). Pp. 191-201.

[3] Kindo, I, Britto, S. J, Arulappan, M. T, Thomas, S, George, M and Marandi, R. (2014). Evaluation of the antioxidant activity of ethanolic extracts of three ethnomedicinal plants. Eur $J$ Biomed Pharm Sci, 1(2). Pp. 190-198.

[4] Liang, L, Zhong, C. C. and Xiao, Z. Y. (1991). Study on chemical constituents of Cipadessacinerascens. Zhongcaoyao, 22. Pp. 6-8.

[5] Luo, X. D, Wu, S. H, Ma, Y. B. and Wu, D. G. (2005). Components of Cipadessabaccifera. Phytochemistry, 5(8). Pp. 867-72.

[6] Thirunavukarasu, T, Santhana Lakshmi, K, Tamilarasan, M, Sivamani, S, Sangeetha, D. and Rajash, T. P. (2014). In vitro antimicrobial, antioxidant, haemolytic, thrombolytic activities and phytochemical analysis of Cipadessabaccifera leaves extracts. Int. J. Phytomed, 6(1). Pp. 109-14. 
[7] Marshall, D. F. (1997). "Meeting training needs in developing countries," in Molecular Genetic Techniques for Plant Genetic Resources. Report of an IPGRI Workshop, W. G. Ayad, T. Hodgkin, A. Jaradat, and V. R. Rao, Eds. Pp. 128-134.

[8] Hubby, J. L. and Lewontin, R. C. (1996). A molecular approach to the study of genetic heterozygosity in natural populations. I. The number of alleles at different loci in Drosophila pseudoobscura. Genetics. 54(2). Pp.577-594.

[9] Powell, W, Morgante, M. and Andre, C, Hanafey, M, Vogel, J, Tingey, S, Rafalski, A. (1996). The Comparison of RFLP, RAPD, AFLP and SSR (microsatellite) marker for germplasm analysis. Molecular Breeding, 2(3). Pp. 225-238.

[10] Russell, J. R, Fuller, J. D, Macaulay, M, Hatz, B. G, Jahoor, A, Powell, W. and Waugh, R. (1997). Direct comparison of levels of genetic variation among barley accessions detected by RFLPs, AFLPs, SSRs and RAPDs. Theoretical and Applied Genetics, 95. Pp.714-722.

[11] Ammiraju, J. S. S, Dholakia, B. B, Santra, D. K, Singh, H, Lagu, M. D, Tamhankar, S. A, Dhaliwal, H. S, Rao, V. S, Gupta, V. S. and Ranjekar, P. K.(2001). Identification of inter simple sequence repeat (ISSR) markers associated with seed size in wheat. Theoretical and Applied Genetics, 102(5). Pp. 726-732.

[12] Ratnaparkhe, M. B, Tekeoglu, M. and Muehlbauer, F. J. (1998). Inter simple sequence repeat (ISSR) polymorphisms are useful for finding markers associated with disease resistance gene clusters. Theor. Appl. Genet, 97(4). Pp.515519.

[13] Sica, M, Gamba, G, Gaudio, L. and Aceto, S. (2005). ISSR markers show differentiation among Italian populations of Asparagus acutifolius L. BMC Genetics. 6(17). Pp. 1-7.

[14] Wolfe, A. D, Xiang, Q. Y. and Kephart, S. R. (1998). Diploid hybrid speciation in Penstemon (Scrophulariaceae). Proc. Natl. Acad. Sci. 95(9). Pp. 5112-5115.

[15] Bornet, B, Muller, C, Paulus, F. and Branchard, M. L. (2002). Highly informative nature of inter simple sequence repeat (ISSR) sequences amplified using triand tetra-nucleotide primers from DNA of cauliflower (Brassica oleracea var. botrytis L.). Genome.45. Pp. 890-896.

[16] Bornet, B. and Branchard, M. (2004). Use of ISSR fingerprints to detect microsatellites and genetic diversity in several related Brassica taxa and Arabidopsis thaliana. Hereditas, 140(3). Pp. 245-248.
[17] Archak, S, Gaikwad, A. B, Gautam, D, Rao, E. V, Swamy, K. R. M. and Karihaloo, J. L. (2003). Comparative assessment of DNA fingerprinting techniques (RAPD, ISSR, and AFLP) for genetic analysis of cashew (Anacardiumoccidentale L.) accessions of India. Genome, 46(3). Pp. 362-369.

[18] Doyle, J. J. and Doyle, J. L. (1987). A rapid DNA isolation procedure for small quantities of fresh leaf tissue. Phytochem. Bulletin, 19. Pp. 11-15.

[19] Sambrook, J. and Russell, D. W. Molecular Cloning. A Laboratory Manual. New York. Cold Spring Harbor Laboratory Press. 2001.

[20] Williams, J. G. K, Kubelik, A. R, Livak, K. J, Rafalski, and Tin-joy, S. V. (1990). DNA polymorphisms amplified by arbitrary primers are useful as genetic markers. Nucleic Acids Res, 18. Pp. 6531-6535.

[21] Nei, M, Li, W. H. (1979). Mathematical models for studying genetic variation in terms of restriction endonucleases. Proc Natl Acad Sci USA. 76. Pp. 5269-5273.

[22] Nei, M. (1973). Analysis of gene diversity in subdivided populations. Proceedings of the National Academy of Sciences of the USA.70. Pp. 3321-3323.

[23] Nei, M. (1978). Estimation of average heterozygosity and genetic distance from a small number of individuals. Genetics. 89(3). Pp. 583-90.

[24] Langridge, P. and Chalmers, K. J. The principle. Identification and application of molecular markers. In. Lorz $\mathrm{H}$ and Wenzel $\mathrm{G}$ eds. Biotechnology in Agriculture and Forestry 55 . Molecular Marker Systems in Plant Breeding and Crop Improvement, chapter 1.1, pp. 3-22. Springer-Verlag. 2004.

[25] Christopoulos, M. V, Rouskas, D, Tsantili, E. and Bebeli, P. J. (2010). Germplasm diversity and genetic relationships among walnut (Juglans regia L.) cultivars and Greek local selections revealed by Inter-Simple Sequence Repeat (ISSR) markers. Scientia Horticulturae. 125(4). Pp. 584-592.

[26] Jabbarzadeh, Z, Khosh-Khui, M, Salehi, H. and Saberivand A. (2010). Inter simple sequence repeat (ISSR) markers as reproducible and specific tools for genetic diversity analysis of Rose species. African Journal of Biotechnology. 9 (37). Pp.6091-6095.

[27] Su, H, Wang, L, Liu, L, Chi, X, Zhang, Y. (2008). Use of inter-simple sequence repeat markers to develop strainspecific SCAR markers for Flammulina velutipes. J. Appl. Genet. 49(3). Pp. 233-235. 